NBER WORKING PAPER SERIES

\title{
RELATIVE PRICE VOLATILITY UNDER SUDDEN STOPS: THE RELEVANCE OF BALANCE SHEET EFFECTS
}

\author{
Guillermo A. Calvo \\ Alejandro Izquierdo \\ Rudy Loo-Kung \\ Working Paper 11492 \\ http://www.nber.org/papers/w11492
NATIONAL BUREAU OF ECONOMIC RESEARCH
1050 Massachusetts Avenue
Cambridge, MA 02138
June 2005

We would like to thank Michael Devereaux and anonymous referees for very useful comments and suggestions, and Omar Zambrano for research assistance. The usual caveats apply. The views expressed herein are those of the author(s) and do not necessarily reflect the views of the National Bureau of Economic Research.

(C2005 by Guillermo A. Calvo, Alejandro Izquierdo and Rudy Loo-Kung. All rights reserved. Short sections of text, not to exceed two paragraphs, may be quoted without explicit permission provided that full credit, including (C) notice, is given to the source. 
Relative Price Volatility Under Sudden Stops: The Relevance of Balance Sheet Effects

Guillermo A. Calvo, Alejandro Izquierdo and Rudy Loo-Kung

NBER Working Paper No. 11492

July 2005

JEL No. F31, F32, F34, F41

\section{ABSTRACT}

Sudden Stops are associated with increased volatility in relative prices. We introduce a model based on information acquisition to rationalize this increased volatility. An empirical analysis of the conditional variance of the wholesale price to consumer price ratio using panel $\mathrm{ARCH}$ techniques confirms the relevance of Sudden Stops and potential balance-sheet effects as key determinants of relative-price volatility, where balance-sheet effects are captured by the interaction of a proxy for potential changes in the real exchange rate (linked to the degree of external leverage of the absorption of tradable goods) and a measure of domestic liability dollarization.

Guillermo A. Calvo Inter-American Development Bank 1300 New York Ave. Washington, DC 20577 and NBER gcalvo@iadb.org

Alejandro Izquierdo Inter-American Development Bank 1300 New York Ave. Washington, DC 20577 alejandroi@iadb.org

Rudy Loo-Kung Inter-American Development Bank 1300 New York Ave. Washington, DC 20577

rudyk@contractual.iadb.org 


\section{Introduction}

The succession of financial crises in Emerging Market economies (EMs) that materialized throughout the second half of the 1990s, ${ }^{1}$ affecting a wide range of countries in terms of standard fundamentals in a relatively short time span, suggests that systemic financial market forces, coupled with specific country vulnerabilities to capital account shocks, lie at the heart of these developments.

The vast literature on contagion in capital markets that emerged following these events acknowledges the existence of systemic effects (or "excess" volatility in spreads and asset prices), and it attempts to identify underlying characteristics that work as coordination factors. For example, contagion between two countries could be due to the fact that they belong to a particular asset class (Rigobón (2001)), borrow from the same banks (van Rijckeghen and Weder (2000)), or share a set of overexposed mutual funds (Broner and Gelos (2003)). Inspired by the Russian crisis of 1998, Calvo (1999) provides a model for contagion based on liquidity shocks to international investors, triggered by developments in a particular country that spread to other countries as international investors sell other assets in their portfolio to restore liquidity.

As a result of contagion, EMs have been subject to large and unexpected falls in capital inflows, or Sudden Stops. Although the origins of Sudden Stops (or "incipient" Sudden Stops) typically reflect systemic shocks to capital markets, the probability that a particular country will experience a full-fledged Sudden Stop with large capital flow reversals could still depend on domestic factors representing vulnerabilities to this external shock. That is, the probability of experiencing a full-fledged Sudden Stop,

\footnotetext{
${ }^{1}$ Starting with the Mexican crisis of 1994-95 and the subsequent crises in East Asia (1997), Russia (1998), and Latin America (1999-2001).
} 
conditional on the materialization of an "incipient" Sudden Stop could be a function of domestic factors.

As established in Calvo, Izquierdo and Mejía (2004), potential balance-sheet effects are key domestic drivers of the probability of experiencing a Sudden Stop. This is mainly due to the fact that Sudden Stops may entail a dramatic change in the level of the real exchange rate (RER). Abstracting from supply-side effects, this is simply the corollary of a cut in current account financing that forces a fall in aggregate demand, which, in turn, induces a drop in the price of non-tradable goods relative to that of tradable goods, ${ }^{2}$ so that the RER (defined as the inverse of this relative price) will rise. This change-in-level effect in the RER becomes larger the less open a country is (i.e., the smaller the supply of tradable goods, ${ }^{3}$ and given supply elasticities), as less tradable resources will be available to cushion the impact of the cut in foreign financing (see Calvo, Izquierdo and Talvi (2003) for details). EMs may find RER fluctuations quite challenging to deal with when their financial systems are dollarized, especially if domestic banks lend to non-tradable sectors in foreign currency. ${ }^{4}$ Thus, this phenomenon that we will refer to as Domestic Liability Dollarization (DLD) is particularly treacherous because Sudden Stops and subsequent RER swings could trigger major uncertainty about the solvency of the banking system as loans become non-performing, sometimes leading to bank runs, which almost inevitably affect the payments system and cause disruption in transactions and output. Thus, the combination of large potential RER fluctuations and

\footnotetext{
${ }^{2}$ Taking the foreign exchange price of tradable goods as given (the standard assumption for a small open economy), all the effect goes through the foreign exchange price of non-tradables.

${ }^{3}$ Relative to the absorption of tradable goods.

${ }^{4}$ See Schmukler and de la Torre (2004) for a discussion on why banks may have a preference for default risk over exchange rate risk.
} 
DLD could prove deadly, as balance-sheet effects kick in and bring about a major shakeup of the domestic banking system.

Building on Calvo, Izquierdo and Mejía (2004), we focus on another (but related) angle of Sudden Stops, namely, the issue of short-term relative price volatility (such as that of the wholesale price index (WPI) to consumer price index (CPI) ratio) and its determinants, with particular emphasis on the impact of balance-sheet effects under Sudden Stop episodes. We care about volatility because when firms are debt-ridden (as is likely to be the case after a capital flow episode) and financial markets do not have access to contingent contracts, relative-price volatility may bring about financial havoc. The reason we believe that balance sheet effects may have an impact on relative price volatility is that the former, by affecting the probability of a Sudden Stop, may lead to higher volatility in aggregate demand.

Related empirical work, such as that of Kaminsky and Reinhart (2001) deals with the behavior of the conditional volatility of high frequency ${ }^{5}$ nominal exchange rate and asset price returns at the country level, and notes that there are periods of global turmoil, where the materialization of spikes in volatility tend to coincide across countries. Hausmann et al (2004) focus instead on the long-run volatility of the real effective exchange rate in an effort to explain differences in the conditional variance of changes in the RER between developing and developed countries. They establish that there is indeed a difference in the persistence of the conditional variance process between developed and developing countries, but no major factor affects the conditional variance of changes in the RER other than perhaps the size of terms of trade shocks.

\footnotetext{
${ }^{5}$ Using daily data.
} 
Our approach is different in that it focuses on the behavior of the WPI to CPI ratio instead of measures of the bilateral or multilateral RER, and it explores the effects of Sudden Stops and balance sheet effects on the conditional variance of this ratio ${ }^{6}$. This relative price has not been as extensively studied as the RER, and, yet, there may be grounds to believe that it may better capture the domestic behavior of the price of tradables vis-à-vis that of non-tradables following Sudden Stop events and devaluation. For example, Burnstein et al (2003) find that during crises, the retail price of tradable goods moves much less than the "at dock" price of imports and exports, which tend to follow nominal exchange rate movements more closely. This is due to the fact that many tradable goods require the use of non-tradable inputs before they reach the retail market, and, thus, their retail price reflects a non-tradable component. Therefore, the WPI, which typically has a sizeable tradable component, may capture more appropriately the behavior of the retail price of tradable goods than the nominal exchange rate. This may be important when analyzing balance-sheet factors because if the domestic price of tradable goods does not track the nominal exchange rate one to one in times of crisis, even tradable sectors may experience problems in a context of high liability dollarization.

A key question that we ask is how Sudden Stops and balance-sheet factors affect the volatility of relative prices. Even though it is clear that Sudden Stops involve major changes in the level of the RER, it is not as clear how the disruption created by Sudden Stops may introduce increased volatility in relative prices. We propose a model where information plays a key role in determining relative price volatility. Sudden Stops

\footnotetext{
${ }^{6}$ The WPI to CPI ratio basically captures a relative price between goods (many of which are tradable, and a substantial component of the WPI) and services (most of which are non-tradable, and a major component of the CPI). Moreover, the basket of goods represented by the WPI may be deemed more relevant for this analysis than that of the CPI of external partners typically used when measuring the real exchange rate.
} 
typically coincide with an increase in systemic risk, which is mirrored by a bigger correlation of investment projects and a consequent increase in the variance of investment portfolios. This increased variance provides an incentive for investors to acquire additional information about investment projects, an action that leads to a larger response from investors to shocks, which, in turn, introduces more volatility in aggregate demand and in relative prices. This framework provides a rationale for the observed relationship between Sudden Stops and increased relative price volatility that is supported by our empirical findings. In a similar fashion, an increase in potential balance-sheet effects due to higher potential changes in the real exchange rate (were a Sudden Stop to materialize) may also provide incentives for investors to acquire additional information, thus introducing further volatility in relative prices.

Casual empirical observation reveals that more than half of Sudden Stops in EMs are associated with spikes in volatility of the WPI to CPI ratio (measured as a substantial increase in the conditional variance of an autoregressive conditional heteroskedasticity (ARCH) specification). This suggests that major relative price turbulence is a key characteristic of Sudden Stop phenomena. Additionally, while close to half of the volatility spikes in the WPI/CPI ratio in EMs coincide with Sudden Stops, only nine percent of these spikes occur during Sudden Stop phases in developed countries, suggesting that Sudden Stops are not a relevant source of relative price volatility for the latter group, but are a factor to consider for EMs.

We test these results formally by estimating a panel $\mathrm{ARCH}$ model of the cyclical component of the WPI to CPI ratio, and find that Sudden Stops do increase the conditional variance of this ratio. Balance-sheet factors, captured by a measure of 
potential changes in the RER, coupled with a measure of domestic liability dollarization are also robust across specifications in explaining increases in the conditional variance.

\section{Sudden Stops and Relative Price Volatility: A Simple Model}

Sudden Stop has become one of the focal points of recent theoretical and empirical analyses of EMs. However, Sudden Stop theory has almost exclusively dealt with level effects, as opposed to volatility effects. The next section will show some striking empirical results about volatility and its relationship with Sudden Stop crises and balance-sheet mismatches. However, these results are hard to interpret without some theoretical background. This motivates the present section.

Second moments are hard to model. Propositions that sound intuitively plausible, and thus general, appear to require very specific assumptions. A prominent example in the volatility literature is Grossman and Stiglitz (1980) (GS). GS addresses a situation in which investors have to choose between a safe and a risky asset. Investors are either Informed or Uninformed. The former have some knowledge about the current realization of the risky asset's return, while the Uninformed have none (they only know ex ante distributions). Thus, the Uninformed base their inference on ex ante information and any thread that they can pull from market prices. The Uninformed can become Informed by paying a fixed cost. In order to obtain reduced forms and be able to characterize equilibrium, GS assumes that the utility function belongs to the Constant Absolute Risk Aversion family, and that random shocks are normally distributed. Under those conditions, GS is able to prove the following two eminently plausible propositions: (a) the volatility of the risky asset's price increases with the volatility of underlying returns 
and informational noise, and (b) the larger the variance of the underlying return and informational noise, the larger will be the share of the Informed. Moreover, (c) price volatility increases with the share of the Informed. The latter is an important insight that may require some discussion to appreciate its intuitive appeal.

Consider first the case in which there are no informed investors and, thus, market prices are dictated by ex ante information. Hence, today's risky-asset price is hit by no random shock and is, consequently, completely stable. In contrast, consider the case in which everyone is Informed. Clearly, under these circumstances there will be information that will filter into the current risky asset's price, increasing its volatility. That the share of informed investors translates into higher price volatility in a monotonic fashion is, however, a result of the special assumptions in GS, but its intuitive plausibility is hard to question.

GS lends itself to a reinterpretation for the case at hand. Thus, for instance, one could associate a Sudden Stop with an increase in the noise factor in GS, which implies higher price volatility for two reasons: (a) larger underlying volatility (this is a direct effect), that (b) induces agents to acquire better information, giving rise to larger price volatility. In addition, the size of the price shock should also be a factor in explaining price volatility on the basis of the following consideration. Price shocks contain idiosyncratic and systemic components, which are not individually observable. Thus, investors face a "signal extraction" problem and, as a general rule, will attach some probability that part of the shock is caused by systemic shocks ${ }^{7}$. Moreover, systemic shocks increase the ex ante correlation among risky assets. Thus, if the model's risky asset is thought of as a "minimum variance" mutual fund of a variety or risky assets, its

\footnotetext{
${ }^{7}$ For example, see Calvo (1999).
} 
volatility will increase. Thus, the larger the observable shock, the higher is the ex ante volatility of the risky asset's price (again based on higher underlying return volatility and incentives for acquiring better information on the part of investors).

Above considerations provide some basis for an $\mathrm{ARCH}$ specification for price volatility. Moreover, this reinterpretation of GS rationalizes the possibility that variables like balance-sheet currency mismatch and current account deficit (as a share of the absorption of tradables) — highlighted in Calvo, Izquierdo, and Mejía (2004)—could also enter as explanatory variables in the $\mathrm{ARCH}$ model. This is so because the larger are the latter two variables, the larger is the probability of Sudden Stop and, hence, the larger the probability that asset prices will become more volatile because of possibly larger informational noise, leading to the acquisition of better information and, according to GS, greater volatility. The empirical analysis will focus on the ratio of wholesale to consumer price levels, some kind of "domestic" real exchange rate. We focus on this variable because it comes closer to a relative price between goods and services than any of the standard measures of real exchange rate. However, this relative price is not the price of an asset. GS, thus, helps to get some intuition about factors that affect price volatility but leaves us somewhere halfway from where we need to go. ${ }^{8}$ This is the motivation for developing the next simple model, where variables are closer to the ones that will be subject to empirical analysis. Moreover, the model will be much simpler than GS, which will help better to understand the basic economics of information and price volatility. A Simple Model of Price Variability. Let us assume that the economy is populated by identical competitive firms producing tradables. Each firm is owned by one entrepreneur

\footnotetext{
${ }^{8}$ Halfway because, for example, the risky asset could be thought as a bundle of different land plots, subject to a stochastic return. Thus, the price of the risky asset would correspond to a price index of land, a nontradable, in terms of the safe asset, a tradable.
} 
whose labor services are fixed and normalized to 1 . Output of tradables is produced by means of capital (a tradable) and entrepreneurial labor services (a non-tradable) under constant returns to scale. Let $k$ denote the capital-(entrepreneurial) labor ratio, and $\theta \mathrm{a}$ random variable with positive variance, which affects the marginal productivity of capital. Thus, denoting the output-labor ratio function by $f(k, \theta)$, we assume that

$$
f(k, \theta)=\theta k-\frac{k^{2}}{2},
$$

Moreover, static quasi-rent per unit of (entrepreneurial) labor, given $k$ and $\theta, \pi(k, \theta)$, satisfies:

$$
\pi(k, \theta)=f(k, \theta)-r k,
$$

where $r$ is the exogenous international interest rate in terms of tradables (or the capital rental).

Consider first the case of the Uninformed who have to choose the level of capital before the state of nature is revealed. The Uninformed know the ex ante distribution of random variable $\theta$, the international interest rate $r$ and, of course, his/her production function. We assume that investors are risk neutral. Thus, the Uninformed will choose the capital-labor ratio $k$ so as to maximize

$$
E \pi(k, \theta)=\bar{\theta} k-\frac{k^{2}}{2}-r k,
$$

where $\bar{\theta} \equiv E \theta$, i.e., the unconditional expectation of $\theta$. Thus, the first-order condition satisfies: ${ }^{9}$

$$
k=\bar{\theta}-r .
$$

\footnotetext{
${ }^{9}$ In what follows, we will focus on interior solutions.
} 
Thus, the Uninformed choose $k$ independently of the realization of random shock $\theta$, and optimal $k$ declines with the international interest rate $r$, as expected. Plugging equation (4) into expression (3) we get the value of expected quasi-rents from the perspective of Uninformed investors. We denote it by $\pi^{U}$. Hence,

$$
\pi^{U}=\frac{(\bar{\theta}-r)^{2}}{2}
$$

Consider now the case of the (perfectly) Informed investor, who is able to pinpoint exactly the realization of random variable $\theta$. Thus, the first-order condition with respect to $k$ yields:

$$
k=\theta-r .
$$

Hence, equation (6) says that the profit-maximizing $k$ increases with random shock $\theta$ and decreases with the international rate of interest $r$, as expected.

Denoting quasi-rents of the Informed investor conditional on $\theta$ by $\pi^{I}(\theta)$, it readily follows, by equations (3) and (6) that

$$
\pi^{I}(\theta)=\frac{(\theta-r)^{2}}{2},
$$

implying that

$$
\underset{\theta}{E} \pi^{I}(\theta)=\underset{\theta}{E} \frac{(\theta-r)^{2}}{2}=\frac{\operatorname{var} \theta}{2}+\pi^{U} .
$$

Therefore, expected quasi-rents of the Informed exceed that of the Uninformed. Thus, if the cost of acquiring information is, say, a positive constant $\sigma$, then everybody will become informed if var $\theta>2 \sigma$, while nobody will invest in information if var $\theta<2 \sigma$. 
This result is in line with GS. However, except in the borderline case in which var $\theta=2$ $\sigma$, all investors are either Informed or Uninformed. ${ }^{10}$

Let us now turn to relative prices. Recalling equations (1), (2) and (4), if all investors are Uninformed the (implicit) real entrepreneurial wage or income in terms of tradables will be

$$
(\bar{\theta}-r)\left(\theta-\frac{\bar{\theta}}{2}-\frac{r}{2}\right)
$$

On the other hand, if all investors are informed, the real entrepreneurial wage is, by (1), (2) and (6),

$$
\frac{(\theta-r)^{2}}{2}
$$

It can be shown that when $\theta$ has a uniform distribution, the variance of the real wage is more volatile under informed investors (see Technical Appendix I). ${ }^{11}$

An interesting implication of this example is that, even though increases in the variance of $\theta$ will, in general, affect the return to (entrepreneurial) labor-both for informed or uninformed investors - the effect of this increase will be bigger when investors are informed than when they are uninformed. In the present model, the key channel establishing a connection between the variability of $\theta$ and that of the real wage is the possibility that investors decide to get better informed. This is the channel that we wish to emphasize. First, because it is lesser known. But, second and more important, because we sense that a major phenomenon that takes place after a Sudden Stop is that individuals have strong incentives to spend more time assessing the situation. This

\footnotetext{
${ }^{10}$ The model could be extended to the case in which individuals face different costs of acquiring information. In this fashion, one could replicate GS's result that there exists a robust set of cases in which Informed and Uninformed investors coexist.

${ }^{11}$ This result also extends to the family of log-normal distributions.
} 
entails looking at variables that would be irrelevant in normal times (e.g., the credit network in which debtors are inserted: are there massive bankruptcies which threaten the ability of clients to repay their debts, etc?). The resulting greater attention to details on the part of entrepreneurs likely slows down the production process bringing about a negative level effect on output. But, in addition, and in line with our example, more detailed information results in greater volatility of investment decisions, thus imparting greater volatility on relative prices, specifically the real entrepreneurial wage (which in our example could be identified with the ratio of the WPI to CPI).

This framework clearly shows that better information leads to higher relative price volatility. However, better information by itself may not be welfare-reducing if it leads to better decision-making on the part of firms. The reason we care about volatility is that when firms are debt-ridden (as is likely to be the case after a capital flow episode) and financial markets do not have access to contingent contracts, relative-price volatility may bring about financial havoc that more than offsets the beneficial effects of better information. This could be particularly true in a context of high Domestic Liability Dollarization, where higher relative-price variance will increase the likelihood of rendering firms bankrupt.'

Thus far, we have assumed that investors can have full or no information. However, this model can be extended in interesting ways by assuming that investors could acquire information of different qualities. Consider a simple example in which variable $\theta$ can take values in the interval $[a, b]$. No information means that investors only know the ex ante distribution of $\theta$, while perfect information means that prior to choosing $k$ investors know $\theta$ with perfect certainty. Let us imagine an intermediate case in which 
investors can tell whether $\theta$ falls on the subinterval $\left[a, \frac{a+b}{2}\right]$ or $\left[\frac{a+b}{2}, b\right]$, but nothing else. Assuming that the underlying distribution for $\theta$ remains invariant, one can show that expected quasi-rents under the intermediate case are larger than under no information and smaller than under full information. This follows from our discussion above, which shows that larger variance of the conditional mean of $\theta$ (conditional on the interval in which $\theta$ falls) upon which investors could react because the information is available to them, leads to higher expected quasi-rents (recall expression (8)). Moreover, one can show that further information refinements of the sort discussed here are associated with larger variance of the conditional mean ${ }^{12}$.

Figure 1 depicts information equilibrium determination. On the horizontal axis we depict information quality (quality improves as numbers get larger). On the vertical axis we depict marginal cost and benefit of information. Equilibrium obtains at point $\mathrm{A}$ where marginal cost equals marginal benefit (measured by quasi-rent). This is completely standard. Less obvious is how equilibrium information quality changes as the variance of ex ante $\theta$ goes up. A simulation study for the case in which $\theta$ is uniformly distributed shows the existence of a robust set of examples in which the marginal benefit from better information increases with the variance of $\theta$ (the simulation exercise is discussed in Technical Appendix II). ${ }^{13}$ In terms of Figure 1, this implies that the

\footnotetext{
${ }^{12}$ In this example, it is clear that the variance of the conditional mean of $\theta$ is higher when investors can tell whether $\theta$ falls on the subinterval $\left[a, \frac{a+b}{2}\right]$ or $\left[\frac{a+b}{2}, b\right]$, than when investors can only tell that $\theta$ falls on the interval $[a, b]$ (in which case, the variance of the conditional mean is zero). See technical appendix II for more on this.

${ }^{13}$ Actually, we have not been able to find a counterexample in which larger variance lowered the marginal benefit of better information.
} 
marginal benefit curve shifts up as the variance of $\theta$ increases, leading to more information in equilibrium. Thus, under these circumstances, larger volatility of fundamentals like $\theta$ induces better information and, consequently, larger relative price volatility.

\section{Sudden Stops and Relative-Price Volatility: Empirical Findings}

The previous section has shown that increased variance in portfolios (due, for example, to increased correlation among investment projects during systemic crises) provides an incentive for investors to acquire additional information about investment projects, leading to a larger response to shocks, which, in turn, introduces more volatility in aggregate demand and in relative prices. In a similar fashion, it could be argued that an increase in the probability of experiencing a Sudden Stop due to potential balancesheet effects (were a Sudden Stop to materialize) implies a larger probability that asset returns will become more volatile, providing incentives to acquire better information and, as it has been argued above, to further volatility in relative prices. With this background in mind, we assess whether relative price turmoil is associated with Sudden Stops and balance-sheet effects.

We start our empirical analysis by reviewing statistical properties of the WPI to CPI ratio for a sample of 32 countries with tight links to world capital markets, $15 \mathrm{EMs}$ and 17 developed economies, for the period 1990-2001 (see the Data Appendix for details). EMs included in the sample are those tracked by JP Morgan's Emerging Market Outlook, reflecting a group of countries that significantly participate in world capital 
markets and are thus prone to Sudden Stops originated in systemic shocks to capital markets.

We first compare the variance of the WPI to CPI ratio in times of systemic Sudden Stops vis-à-vis "tranquil" times. ${ }^{14} 15$ For each of the countries in our sample that experienced Sudden Stops, we construct the ratio of the variance in Sudden Stop times relative to tranquil times. We find that, on average, this ratio is close to 2.6 for the case of EMs (see Table 1), suggesting signs of substantial changes in relative price volatility around periods of capital flow reversals.

We study this more closely by fitting an AR(1) process recursively to the WPI to CPI ratio for each country, and looking at the behavior of one-step-ahead forecast errors. As shown in Figure 2, we find that in many cases, one-step-ahead forecast errors exceeding two standard deviations coincide with Sudden Stop episodes, particularly around the Russian crisis of $1998 .{ }^{16}$ The timing of exceedingly large shocks is indicative of higher volatility around Sudden Stops.

This result warrants an analysis allowing for the possibility of a non-constant conditional variance process of the WPI to CPI ratio. In the same vein as Kaminsky and Reinhart (2001), and under the assumption of a stationary conditional variance process in

\footnotetext{
${ }^{14}$ Cyclical components (obtained using a Hodrick-Prescott filter) are used for this analysis.

${ }^{15}$ The measure of Sudden Stop used here is quite similar to that in Calvo, Izquierdo and Mejía (2004) (see their original formulation for details). In addition to the criterion of large capital flow reversals exceeding two standard deviations from the mean, we request that these reversals be accompanied by a spike in some external aggregate measure of the cost of funds (such as the Emerging Market Bond Index (EMBI) for EMs) in order to capture systemic effects. (see the Data Appendix for more details).

${ }^{16}$ The recursively estimated AR(1) coefficient is relatively stable, even under Sudden Stop episodes, i.e., no two-standard deviation band falls fully outside the interval defined by previousperiod two-standard deviation bands. This ensures that no changes in the structure of the model are passed on to the error term.
} 
relative prices, we estimate standard autoregressive conditional heteroskedasticity

$(\mathrm{ARCH})$ models for each country, of the type:

$$
\begin{aligned}
& p_{t}=\alpha p_{t-1}+u_{t} \\
& \sigma_{t}^{2}=\beta_{0}+\sum_{j=1}^{k} \phi_{i} u_{t-j}^{2},
\end{aligned}
$$

where $p_{t}$, the cyclical component of the WPI to CPI ratio, follows an autoregressive firstorder process, $u_{\mathrm{t}}$ is the disturbance term, and $\sigma_{t}^{2}$ is the conditional variance of $p_{t}$, which follows a moving average process in the innovations $u_{t}^{2} \cdot{ }^{17}$ Results widely confirm the presence of changes in volatility. Figures $3 \mathrm{a}$ and $3 \mathrm{~b}$ display conditional volatility for the period 1992-2001 in EMs and developed countries, respectively, together with Sudden Stop phases (indicated by areas in gray). They suggest that Sudden Stops are in many cases associated with spikes in conditional volatility (which we define as a value for the conditional variance exceeding two standard deviations above the mean). Based on this data, we construct a set of statistics shown in Table 2. For EMs, 56 percent of Sudden Stops come together with spikes in volatility (either contemporaneously or up to six months away from a Sudden Stop phase). For the very few developed economies that were subject to Sudden Stops (4 out of 18 in our sample), 60 percent of Sudden Stops are also associated with spikes in volatility. These figures suggest that Sudden Stops typically come hand-in-hand with increasing relative price volatility. More interestingly, more than 40 percent of all volatility spikes in EMs are associated with Sudden Stops.

\footnotetext{
${ }^{17}$ Our modeling strategy relies on standard joint significance Lagrange multiplier tests, together with likelihood ratio tests, to select an appropriate $\mathrm{ARCH}$ specification for the conditional variance, which is confronted against a standard $\operatorname{GARCH}(1,1)$ specification based on the value of their likelihoods. Whenever the GARCH(1,1) likelihood is greater than the ARCH one, we select the GARCH $(1,1)$ model. This methodology led to the specification of an ARCH process of order 6 or lower for all countries but one, where a GARCH(1,1) process was selected.
} 
This looks quite different for developed countries, where only 9 percent of the spikes are accompanied by Sudden Stops, indicating that Sudden Stops are not a major source of disruption in developed economies, but that Sudden Stops could be a significant factor behind increases in relative price volatility across EMs.

We now proceed to test these results formally by making use of panel ARCH estimations, including 29 out of all 32 countries in our sample ${ }^{18}$. Our interest lies in identifying determinants of the conditional variance of the WPI to CPI ratio linked to Sudden Stops and balance-sheet effects, controlling for additional factors affecting the mean and variance of the WPI to CPI ratio. The general form of the model we estimate is:

$$
\begin{gathered}
p_{i, t}=\sum_{j=1}^{n} \alpha_{j} p_{i, t-j}+\sum_{j=1}^{n} y_{i, t-j}+\lambda \sum_{j=1}^{n+1} t o t_{i, t-j+1}+\delta S S_{i, t}+\xi S S_{i, t}\left(1-\omega_{i, t-1}\right) D L D_{i, t-1}+u_{t} \\
\sigma_{i, t}^{2}=e^{\beta_{0}+\gamma E M_{i}+\eta S S_{t}+\kappa(1-\omega)_{i, t-1}+\mu D L D_{t-1}+\pi E R_{t-1}}+\sum_{j=1}^{k} \phi_{i} u_{t-j}^{2}
\end{gathered}
$$

where $y$ is (the cyclical component of) industrial production, tot represents (the cyclical component of) terms of trade, $S S$ is an indicator variable of Sudden Stop defined along the lines of Calvo, Izquierdo and Mejía (2004) (but incorporating systemic factors, see footnote 15$), E R$ is an indicator variable of exchange-rate-regime flexibility, $1-\omega$ is a measure of potential changes in the real exchange rate, DLD represents liability dollarization, and EM is an emerging market dummy. This specification basically defines the WPI to CPI ratio as an autoregressive process (controlling for a measure of the activity level, $y$, and an external price, tot), where its conditional variance is affected

\footnotetext{
${ }^{18}$ Data on the WPI for Australia, New Zealand, and Nigeria is not available on a monthly basis, so these countries were excluded from the sample.
} 
by the materialization of Sudden Stops and balance-sheet effects, as well as (the square of) past shocks to the mean of the WPI to CPI ratio (implying an $\mathrm{ARCH}(k)$ structure for the conditional variance). ${ }^{19}$

Balance-sheet effects are captured by the interaction of two variables, one measuring real exchange rate changes, the other indicating the base over which valuation effects take place. We use Calvo, Izquierdo and Mejía (2004)’s proxy for potential changes in the real exchange rate following a Sudden Stop, 1- $\omega$, where $\omega$ is defined as the share of the absorption of tradable goods $(Z)$ that can be financed with the existing supply of tradable goods $(Y)$, net of factor payments $(S)$, or $\omega=(Y-S) / Z$. The higher the value of $1-\omega$, the higher the leverage with the rest of the world, and the larger the unavoidable rise in the RER. ${ }^{20}$

As indicated in the introduction, dollarization of the banking system is key in the analysis of the effects of mismatches and balance-sheet effects because bankruptcies of non-tradable sectors indebted in foreign currency can lead to heavy stress on banks and on the payments system. Constructing a measure of loans allocated to non-tradable sectors in foreign currency (net of assets in foreign currency) is not possible for our sample size given lack of data. Instead, we rely on a proxy using a measure of Domestic Liability Dollarization, or DLD. It is defined as BIS reporting banks' local asset positions in foreign currency as a share of GDP for the case of developed countries. Given that such data is not available for EMs, we construct a proxy for DLD by adding

\footnotetext{
${ }^{19}$ All variables in the variance equation are lagged one period to reduce potential endogeneity problems, except for the Sudden Stop indicator, which is set contemporaneously.

${ }^{20}$ Given the lack of monthly national account data, we proxy our measure of $(1-\omega)$ by the ratio of exports over imports, assuming that exports are a good representation of the supply of tradable goods, and that imports are a good proxy of the absorption of tradable goods.
} 
up dollar deposits ${ }^{21}$ and bank foreign borrowing as a share of GDP, under the assumption that banks match their assets and liabilities by currency type, and transfer exchange rate risk to debtors ${ }^{22}$ Although this variable is not exactly a measure of mismatch because some of the credit in foreign currency may be allocated to tradable sectors (and some non-tradable sectors may possess assets in foreign currency), some recent evidence based on Kamil (2004) suggests that high levels of dollarization are typically accompanied by currency mismatches, in which case it constitutes a reasonable proxy. Note that DLD is measured as a share of GDP because it better captures the potential impact of balancesheet effects in terms of the size of the economy, as opposed to measures that consider the share of dollar loans in total loans - measures that, although possibly high, are not good indicators of the size of the balance-sheet problem.

Notice that since the second term of the right hand side of the variance equation (13) is non-linear, there is an implicit interaction between (1- $\omega$ ) and DLD (given that the impact of $(1-\omega)$ on relative price volatility will depend on the level of DLD) that accounts for balance-sheet effects.

Because volatility is typically higher in EMs than in developed economies due to differences in several other institutional factors, we include an EM dummy to capture these effects. Another element to consider is that more flexible exchange rate regimes will typically display higher volatility of the WPI to CPI ratio. We include Reinhart and Rogoff's (2002) measure of nominal exchange rate flexibility to control for this effect.

\footnotetext{
${ }^{21}$ Data on dollar deposits are mainly those from Honohan and Shi (2003); see the Data Appendix for a full description.

${ }^{22}$ See IDB (2004) for evidence on the high correlation across countries between the levels of domestic deposit and loan dollarization, reflecting the existence of prudential measures that limit net foreign exchange positions at the bank level.
} 
More general specifications also control for possible effects of Sudden Stops, the exchange rate regime, and the interaction of Sudden Stops with potential changes in relative prices (1- $\omega)$ and dollarization (DLD) on the mean of the WPI to CPI ratio.

Estimation of system (12)-(13) requires selecting an appropriate lag length $(n)$ for variables in the mean equation, as well as an appropriate lag length for the $\mathrm{ARCH}$ terms of the conditional variance. Our strategy is to first choose lags ( $n$ ) of $p, y$ and tot in (13) as indicated by a Schwarz information criterion ${ }^{23}$. Next, we use the squared residuals obtained from estimation of (12) to select the appropriate lag length $(k)$ of the ARCH component of (13) with the aid of LM tests and Likelihood Ratio tests. ${ }^{24}$ This procedure leads to the selection of an $\mathrm{ARCH}(6)$ model for the conditional variance $\left(k=6\right.$ in (13)) ${ }^{25}$. Results for the ARCH(6) model are presented in Table 3, for different specifications regarding the number of controls used in the mean and variance equations. Columns 1 and 2 show the simplest specifications ( $\delta=\xi=0$ ), assuming that Sudden Stops, or Sudden Stops interacted with potential balance-sheet effects captured by $(1-\omega)$ and DLD, have no significant impact on the mean equation of relative prices. Columns 3 and 4 add the Sudden Stop indicator in the mean equation $(\delta \neq 0)$. Columns 5 and 6 add the interaction of Sudden Stop and potential balance-sheet effects $(\xi \neq 0)$, while columns 7 and 8 include

\footnotetext{
${ }^{23}$ Departing from an "unrestricted" model for $p$ including 6 lags of $p, y$ and tot. This is done for parsimony reasons in order to minimize noise.

${ }^{24}$ Departing from an "unrestricted" model for the squared residuals including 6 lags.

${ }^{25}$ An identification problem arises when trying to specify the lag structure of the mean equation and that of the conditional variance equation simultaneously. The lag structure of the mean equation could be fixed first, proceeding afterwards with the identification of an appropriate lag structure for the conditional variance, under the assumption that the true process of the mean equation is known. Alternatively, the structure of the conditional variance could be fixed first, proceeding afterwards with the choice of an appropriate lag structure in the mean equation, this time under the assumption that the true process of the variance is known. Both approaches are not without caveats. Ideally, joint identification of the appropriate lag structure of both mean and variance should be carried out, a task that involves maximizing the likelihood of a family of models with different lag lengths in mean and variance, something that we do not do here.
} 
both the Sudden Stop indicator and balance-sheet effects $(\delta \neq 0, \xi \neq 0)$. In addition, columns 2, 4 and 6 also capture the effects of the inclusion of the exchange rate regime in the conditional variance equation $(\pi \neq 0)$. For all specifications in Table 3, LM tests were run on the squared standardized residuals to check for possible remaining autocorrelation ${ }^{26}$. None were significant at the 5 percent level, providing evidence that ARCH effects have been appropriately captured by the $\mathrm{ARCH}(6)$ specification.

A common feature across the different estimations is the significance of the Sudden Stop indicator variable at the 1 percent level in the conditional variance equation. DLD also comes up significant at the 1 percent level, with a positive coefficient. (1- $\omega)$ is significant at the 10 percent level in the estimation shown in column 1 , and at the 12-16 percent level in most other specifications shown in Table 3. Even though the inclusion of the Sudden Stop indicator and the balance-sheet effect measure may be justified on economic grounds, they do not come up significant in the mean equation (columns 3-8). Note that the lack of significance of these variables does not invalidate the fact that Sudden Stops could still have level effects on relative prices. Because these events may, for example, be associated with an overshooting of the real exchange rate at the onset of a crisis, not necessarily implying that relative prices should remain constant at a high level within the Sudden Stop window, our Sudden Stop indicator need not be significant. However, this window is indeed relevant in defining periods of turbulence in relative prices, as shown by its significance in the variance equation.

\footnotetext{
${ }^{26}$ Standardized squared residuals are obtained by dividing squared residuals in equation (12) by the estimated conditional variance (from equation (13)). If the ARCH specification has appropriately captured the structure of the conditional variance, squared standardized residuals should display no signs of autocorrelation (see Bollerslev and Mikkelsen (1996)). This is verified by running LM tests using six lags of the squared standardized residuals.
} 
The fact that the Sudden Stop indicator and the balance-sheet effect variable turn out not to be significant in the mean equation suggests one should refer to columns 1 and 2 when analyzing the effects of $(1-\omega)$. Even though $(1-\omega)$ is significant at the 10 percent level in the estimation shown in column 1, after the inclusion of the exchange rate regime variable (column 2$),(1-\omega)$ is significant only at the 12 percent level. These results provide some evidence for the presence of balance-sheet effects affecting the conditional variance of relative prices. Additionally, the EM dummy is significant at the 1 percent level, while the exchange rate regime indicator variable is significant at the 5 percent level across different specifications.

Reflecting on the choice of (1- $\omega)$, we notice that previous work by Calvo, Izquierdo and Mejía (2004), using yearly data, rely on the first lag of (1- $\omega)$ to account for balance-sheet effects, which is equivalent in our specifications to a 12-month lag. Their result may be highlighting that the longer lag of (1- $\omega)$ is a better proxy for the potential change in the real exchange rate (following a Sudden Stop) than the first lag of $(1-\omega)$, which may already be showing signs of adjustment, similar to the one that would prevail at the time of a Sudden Stop. For this reason, we decide to include a 12-month lag of (1$\omega)$ in our specifications.

Another element of possible concern is that the high frequency nature of the series used for estimation may reduce the power of lagging explanatory variables one period to reduce possible endogeneity problems in the ARCH specifications. For this reason (and the economic justification for the inclusion of a 12-month lag of (1- $\omega$ ) previously stated), 
we perform a robustness check including 12-period lags for all variables in our variance equation (DLD, $(1-\omega)$, and the exchange rate regime). Results are shown in Table $4 .^{27}$

This specification clearly states the relevance of $(1-\omega)$ in the variance equation, which comes up significant at the 1 or 5 percent level, depending on the specification. DLD also remains significant, at the 1 percent level. These results provide stronger evidence in favor or the influence of balance-sheet effects in determining the conditional variance of the WPI to CPI ratio. The Sudden Stop indicator also stays significant at the 1 percent level, while the exchange rate regime is significant at the 10 percent level.

All in all, this set of results points to the significance of Sudden Stops and potential balance-sheet effects in affecting the conditional variance of the WPI to CPI ratio. These effects seem to be even stronger for EMs, given the impact of institutional differences with developed countries.

Given these results, it is worth exploring balance-sheet effects further by illustrating the differences in the impact of changes in $(1-\omega)$ on the conditional variance of the WPI to CPI ratio, depending on the level of dollarization, everything else equal. Take for example two EMs whose only difference lies in their dollarization level, i.e., one with high DLD, and another one with low DLD. The ratio of the derivative of (13) with respect to $(1-\omega)$ for the high DLD country vis-à-vis that of the low DLD country yields:

\footnotetext{
${ }^{27}$ Just like before, LM tests were run for all specifications in Table 4 on their squared standardized residuals to check for possible remaining autocorrelation. None were significant at the 5 percent level, once again providing evidence in favor of the $\mathrm{ARCH}(6)$ specification as an appropriate specification of the conditional variance.
} 


$$
\frac{\left.\frac{\partial \sigma_{i, t}^{2}}{\partial\left(1-w_{i, t-1}\right)}\right|_{D L D^{\text {high }}}}{\left.\frac{\partial \sigma_{i, t}^{2}}{\partial\left(1-w_{i, t-1}\right)}\right|_{D L D^{\text {low }}}}=e^{\mu\left(D L D^{\text {high }}-D L D^{\text {low }}\right)}
$$

Now define a high dollarization country as that belonging to the $75^{\text {th }}$ percentile in the DLD sample distribution, and a low dollarization country as that belonging to the $25^{\text {th }}$ percentile. In this case, the ratio of derivatives described in (14) yields 1.467 , indicating that the effect of a change of the same magnitude in $(1-\omega)$ is 46.7 percent higher for the high DLD country.

However, a much more interesting comparison arises when considering the effects of a change in $(1-\omega)$ on the conditional variance of the WPI to CPI ratio for the average EM and under Sudden Stop, vis-à-vis the average developed country with no Sudden Stop (the typical case for developed countries). Assuming away differences in (1- $\omega)$ and the exchange rate regime, we obtain:

$$
\frac{\left.\frac{\partial \sigma_{i, t}^{2}}{\partial\left(1-w_{i, t-1}\right)}\right|_{D L D^{E M}}}{\left.\frac{\partial \sigma_{i, t}^{2}}{\partial\left(1-w_{i, t-1}\right)}\right|_{D L D^{D E V}}}=e^{\mu\left(D L D^{E M}-D L D^{D E V}\right)+\gamma+\eta},
$$

where $\mathrm{DLD}^{\mathrm{EM}}$ is the average DLD level for EMs, $\mathrm{DLD}^{\mathrm{DEV}}$ represents the average DLD level for developed countries, $\gamma$ is the additional effect of being an EM, and $\eta$ is the additional effect of a Sudden Stop. In this case, results are much more striking. Equation (15) yields a value of 6.6, i.e., the effect of a change in $(1-\omega)$ is more than six times bigger for the average EM under Sudden Stop than for the average developed country. A question that arises naturally is how this result should be measured against the fact that 
conditional variances are different between EMs and developed countries. According to (13), the conditional variance for the average EM (evaluated at the mean of all explanatory variables for EMs), is 5.9 times larger than that of a developed country. ${ }^{28}$ Even though the conditional variance of the WPI to CPI ratio is much higher than that of the average developed country, balance-sheet effects due to a change in (1- $\omega)$ will still have a slightly larger proportional impact on the conditional variance of the EM economy.

\section{Conclusions}

Using a theoretical model based on information acquisition under increased uncertainty, we rationalize why Sudden Stops and balance-sheet effects may affect the variance of key relative prices such as the WPI to CPI ratio. Increased variance (due, for example, to increased correlation among investment projects during Sudden Stop episodes) spurs investors to acquire additional information, which translates into greater volatility in investment decisions and in relative prices. In a similar fashion, it can be argued that an increase in the probability of experiencing a Sudden Stop due to an increase in potential balance-sheet effects implies a larger probability that asset returns will become more volatile, providing incentives to acquire better information and leading to further volatility in relative prices.

Casual observation of the properties of a key relative price such as the WPI to CPI ratio, a measure of the "domestic" real exchange rate, suggests that Sudden Stops are associated with increases in this ratio's volatility. In particular, major changes in

\footnotetext{
${ }^{28}$ This time evaluating all explanatory variables at their developed-country mean values.
} 
volatility are associated more than 40 percent of the time with Sudden Stops in EMs, but rarely so in developed countries.

Formal empirical analysis of the determinants of the conditional variance of the WPI to CPI ratio under a family of ARCH specifications confirms that Sudden Stops, as well as potential balance-sheet effects, are highly relevant in understanding sharp increases in volatility. The effects that these balance-sheet factors impinge on the conditional variance of the WPI to CPI ratio are consistent with our previous finding that balance-sheet effects affect the probability of experiencing a Sudden Stop, once informational aspects highlighted by our theoretical model are factored in. In the world of EMs, where contingent contracts are more fiction than fact, sharp increases in relativeprice volatility during a Sudden Stop could have substantial welfare effects.

These results contribute to the expansion of a research program on factors affecting the volatility of relative prices, a key element that needs to be more widely understood given its relevance in the design of policies for EMs, where reduction of volatility and policymaking under high volatility rank at the top of the research agenda. 


\section{Technical Appendix I}

Proposition: For $\theta$ uniformly distributed along the interval $[a, b]$, with $b>a$ and $a>r^{29}$, the variance of the return to entrepreneurial labor under full information, relative to the variance of the return to entrepreneurial labor under no information is greater than 1.

Proof: Recalling (10) and (11) in the main text, the above mentioned ratio reduces to:

$$
R=\frac{\operatorname{VAR}\left[\frac{(\theta-r)^{2}}{2}\right]}{\operatorname{VAR}\left[(\bar{\theta}-r)\left(\theta-\frac{\bar{\theta}}{2}-\frac{r}{2}\right)\right]}=\frac{\frac{1}{4} \operatorname{VAR}\left[(\theta-r)^{2}\right]}{(\bar{\theta}-r)^{2} \operatorname{VAR}(\theta)} .
$$

Given that random variable $\theta$ is uniformly distributed on the interval $[a, b]$, its ex ante mean is $\mu=(a+b) / 2$, and $\operatorname{var} \theta=(b-a)^{2} / 12$. Making use of the fact that

$\operatorname{VAR}(g(x))=\int_{x}[g(x)-E(g(x))]^{2} f(x) d x$, we can rewrite (A1) as:

$$
R(b)=\frac{\frac{1}{4} \int_{a}^{b}\left((\theta-r)^{2}-\int_{a}^{b}(\theta-r)^{2} \frac{1}{(b-a)} d \theta\right)^{2} \frac{1}{(b-a)} d \theta}{\left(\frac{a+b}{2}-r\right)^{2} \frac{(b-a)^{2}}{12}}
$$

For any given $a$, the variance of $\theta$ increases as $b$ increases. Thus, we are interested in the behavior of $R(b)$ as $b$ increases. From (A1), for the particular case of $\operatorname{VAR}(\theta)=0(b=a$, or $\bar{\theta}=\theta$ ), it is clear that $R=1$. Now consider the derivative of (A2) with respect to $b$. This yields:

$$
R^{\prime}(b)=-\frac{4(a-b)(a-r)}{15(a+b-2 r)^{3}}
$$

\footnotetext{
${ }^{29} a>r$ is required so that capital ( $k$ ) is always positive (recall equation (6) in the main text).
} 
Given that $b>a$ and $a>r$, for (A3) to be positive, $a+b-2 r>0$ must hold. Suppose not.

Then:

$$
a+b-2 r<0, \text { or } a-r+b-r<0 \text {. }
$$

But given $b>a>r$ holds, then $a-r>0$ and $b-r>0$, so (A4) can never hold. Therefore, (A3) will always be positive for $b>a$. From the fundamental theorem of calculus, for any $b>a$, we know:

$$
R(b)=R(a)+\int_{a}^{b} R^{\prime}(s) d s=1+\int_{a}^{b} R^{\prime}(s) d s
$$

But given that $R^{\prime}(s)>0$ for any $b>a$ (and zero for $b=a$, recall (A3)), then $R(b)$ will always be greater than 1 . 


\section{Technical Appendix II}

We will sketch out the simulation exercise mentioned in Section III. Let us assume that random variable $\theta$ is uniformly distributed on the interval $[a, b]$. Thus, its ex ante mean is $\mu=(a+b) / 2$, and $\operatorname{var} \theta=(b-a)^{2} / 12$. Under no information, the investor knows the ex ante distribution of $\theta$, but nothing else about its realization. Furthermore, under perfect information the investor knows the exact realization of $\theta$. In the simulation, however, we further assume that the investor can get finer information sets, indexed by $n$, with the following characteristics: consider the grid in the $[a, b]$ interval, denoted by $\{a, a+h, a+2 h, a+3 h, \ldots, b\}$, where $h=(b-a) / n$; having spent resources to acquire a given grid (i.e., a given $n$ ) the investor can tell in what section of the grid random variable $\theta$ has fallen. Thus, for example, the investor may know that the realization of $\theta \in[a+(j-$ 1) $h, a+j h]$, for some natural number $j$ such that $n \geq j \geq 1$. Armed with that information, thus, the investor would be able to compute the conditional expectation of $\theta$, which we will denote $x_{j}(n), j=1,2, \ldots n$. Clearly,

$$
x_{j}(n)=a+\frac{j+j-1}{2} h
$$

All components of the grid have equal probability $1 / n$. It can be verified that ex ante

$$
E x_{j}(n)=\mu \text {. }
$$

In words, the unconditional expected value of $x$ is equal to the unconditional mean of $\theta$, as intuition would suggest. Clearly, the expected value of $x$ is independent of $n$. Thus, to figure out how the variance of $x$ changes with $n$ all we need to do is to compute $\operatorname{Ex}_{j}^{2}(n) .{ }^{30}$

\footnotetext{
${ }^{30}$ Recall that for any random variable $y$, var $y=E y^{2}-(E y)^{2}$. In the above example, the mean of $x$ is constant with respect to $n$. Thus, changes in its variance with respect to $n$ can be assessed by simply examining changes in $E x^{2}$.
} 
Clearly, by (A6) and recalling that $h=(b-a) / n, \mu=(a+b) / 2$ and the probability of each grid is $1 / n$, we have:

$$
\operatorname{Ex}_{j}^{2}(n)=\sum_{j=1}^{n}\left(a+\frac{2 j-1}{2} h\right)^{2} \frac{1}{n}=\sum_{j=1}^{n}\left(a+(2 j-1) \frac{\mu-a}{n}\right)^{2} \frac{1}{n} .
$$

Thus, for each $a$, the marginal benefit of better information, $\Phi(n, a), n=1,2, \ldots, n-1$, is obtained by computing

$$
\Phi(n, a)=\operatorname{Ex}_{j}^{2}(n+1)-\operatorname{Ex}_{j}^{2}(n)
$$

Simulations show that function $\Phi(n, a)$ is downward sloping in $n$ and $a$ for a wide variety of cases (we found no counterexamples). The relationship between $\Phi$ and $n$ is depicted by the downward sloping curve in Figure 1 . Moreover, since $\mu=(a+b) / 2$, and var $\theta=$ $(b-a)^{2} / 12$, it follows that

$$
\operatorname{var} \theta=\frac{(\mu-a)^{2}}{3}
$$

Hence, since $a<\mu$, we have that the variance of $\theta$ declines as $a$ goes up. Therefore, in view of (A9), (A10) and simulations' results, one concludes that there exists a wide variety of cases in which the marginal benefit of information declines as the variance of $\theta$ goes down, as claimed in the text. (Once again, no counterexample to this proposition was found in the simulations.) If this is coupled with an information cost function that is strictly convex and increasing in $n$, equilibrium information quality is determined as in Figure 1. 


\section{Data Appendix}

Our sample of EMs consists of those countries tracked by JP Morgan's Emerging Market Outlook (which includes the subset of countries used in the calculation of the EMBI+ index), i.e., EMs that significantly participate in world capital markets. Countries with missing information on their monthly trade balance, or which do not report quarterly capital account information (a measure we used to check the accuracy of our monthly proxy in mimicking quarterly fluctuations) were dropped from the sample. The complete list of EMs included therefore consists of Argentina, Brazil, Chile, Colombia, Czech Republic, Ecuador, Indonesia, Korea, Mexico, Nigeria, Peru, Philippines, Thailand, Turkey, and South Africa. Our choice of developed countries is dictated by OECD membership, and it includes Australia, Canada, Denmark, Finland, France, Germany, Italy, Japan, Netherlands, New Zealand, Norway, Portugal, Spain, Sweden, Switzerland, United Kingdom, and USA. Data are collected on an annual basis unless otherwise stated.

\begin{tabular}{ll}
\hline \multicolumn{1}{c}{ Variable } & \multicolumn{1}{c}{ Definitions and Sources } \\
\hline Capital flows proxy & Trade balance minus changes in international reserves (monthly). All figures are expressed in 1995 \\
& US dollars. Source: IMF IFS. This data is used to construct a measure of capital flow reversals (see \\
& Sudden Stop indicator in this appendix). \\
The measure of Sudden Stop used here is quite similar to that in Calvo, Izquierdo and Mejía (2004) \\
(see their original formulation for details). In addition to their criterion of large capital flow \\
reversals exceeding two standard deviations from the mean (for their capital flow proxy), we request \\
that these reversals be accompanied by a spike in some external aggregate measure of the cost of \\
funds in order to capture systemic effects. More specifically, we use the (log of) J. P. Morgan \\
Emerging Market Bond Index (EMBI) spread over US Treasury bonds for EMs, the Merrill Lynch \\
Euro-area Government Index spreads for Euro-area countries (as well as Nordic countries such as \\
Denmark, Norway, and Sweden), and G7 Government Index spreads for all remaining developed \\
countries. We construct aggregate high-spread episodes in analogous fashion to the Calvo, \\
Izquierdo and Mejía (2004) measure of large capital flow reversals (i.e., we consider spikes in \\
spreads exceeding two standard deviations from the mean), and consider that a Sudden Stop occurs \\
when the measure of the fall-in-capital-flows phase overlaps (on a yearly basis) with the aggregate \\
high-spread phase. Episodes that lie within a six-month interval are considered part of the same \\
Sudden Stop phase (this Sudden Stop measure differs from Calvo, Izquierdo and Mejía (2004) in \\
that we do not use their second criterion of associated falls in GDP, and instead use the aggregate \\
spread measure described above to consider systemic Sudden Stops). \\
Imports plus tradable output domestically consumed, proxied by the sum of agricultural and \\
industrial output minus exports. More specifically, we construct the share of tradable output in total
\end{tabular}


CAD

Domestic Liability Dollarization

TOT

Ex. Regime RR.

CPI

WPI

Ind. Production output as the ratio of agriculture plus industrial output to total GDP at constant prices. Next, we multiply this share by total dollar GDP to obtain the dollar value of tradable output. We do this in order to avoid excessive fluctuations in output composition due to valuation effects that are present in sectoral data at current prices. Source: World Bank, World Development Indicators.

Current account deficit. Source: IMF’s World Economic Outlook (WEO) database.

For developed economies: BIS reporting banks' local asset positions in foreign currency as a share of GDP (since data for Australia and New Zealand are not available from this source, we used data from their respective Central Banks). For emerging economies: dollar deposits obtained from

Honohan and Shi (2002) (and complemented with data from Central Banks for the cases of Colombia, Korea, Brazil) plus bank foreign borrowing (IMF IFS banking institutions line 26c) as a share of GDP. GDP data was obtained from IMF's WEO database.

We used the ratio of the monthly unit value of exports to the unit value of imports. Both series were obtained mainly from the IMF IFS Database. Missing data was completed using official sources (Central Bank databases).

Monthly 5-way exchange regime classification. Source: Reinhart and Rogoff (2002).

Consumer Price Index. Source: IMF IFS

Wholesale Price Index. Source: IMF IFS

Industrial Production Index (seasonally adjusted). Source: IMF IFS. 


\section{References}

Aghion, P., Bacchetta P., Banerjee, A., 2001. Currency Crises and Monetary Policy in an Economy with Credit Constraints. European Economic Review 45, 1121--1150.

Bollerslev, T., Mikkelsen H., 1996. Modeling and Pricing Long-Memory in Stock Market Volatility. Journal of Econometrics 73 (1), 151--184.

Broner, F., Gelos, R., 2003. Testing the portfolio channel of contagion: the role of risk aversion. Mimeo, Universitat Pompeu Fabra.

Burstein, A., Eichenbaum, M., Rebelo S., 2003. Large Devaluations and the Real Exchange Rate. UCLA online working paper 267.

Calvo, G.A., 1998. Capital Flows and Capital-Market Crises: The Simple Economics of Sudden Stops. Journal of Applied Economics (CEMA) 1 (1), 35--54. Also in Calvo (2005).

Calvo, G.A., 1999. Contagion in Emerging Markets: When Wall Street is a Carrier. In: Calvo, G., Emerging Capital Markets in Turmoil: Bad Luck or Bad Policy?. The MIT Press, Cambridge, MA. Also in www.bsos.umd.edu/econ/ciecalvo.htm.

Calvo, G.A., 2005, Emerging Capital Markets in Turmoil: Bad Luck or Bad Policy?. The MIT Press, Cambridge, MA.

Calvo, G.A., Izquierdo A., Talvi E., 2003. Sudden Stops, the Real Exchange Rate and Fiscal Sustainability: Argentina’s Lessons. In: Alexander V., Mélitz J., von Furstenberg G.M.. (Eds.), Monetary Unions and Hard Pegs. Oxford University Press, Oxford, UK, pp. 150--181. Also in Calvo (2005).

Calvo, G. A., Izquierdo, A., Mejía, L.F., 2004. On the Empirics of Sudden Stops: The Relevance of Balance-Sheet Effects. NBER Working Paper 10520.

de la Torre, A., Schmukler, S., 2004. Coping with Risk through Mismatches: Domestic and International Financial Contracts for Emerging Economies. World Bank. Washington, DC, USA.

Grossman, S., Stiglitz, J., 1980. On the Impossibility of Informationally Efficient Markets. American Economic Review 70, 393--408.

Hausmann, R., Panizza, U., Rigobón, R., 2004. The Long-run Volatility Puzzle of the Real Exchange Rate. NBER Working Paper 10751. 
Honohan, P., Shi, A., 2002. Deposit Dollarization and the Financial Sector in Emerging Economies. World Bank Working Paper No. 8880.

Inter-American Development Bank, 2004. Unlocking Credit: The Quest for Deep and Stable Bank Lending. 2005 Economic and Social Progress Report. Johns Hopkins University Press, Washington, DC, USA.

Kamil, H., 2004. A new database on the currency composition and maturity structure of firms’ balance sheets in Latin America, 1990-2002. Mimeo.

Kaminsky, G., Reinhart, C., 2001. Financial Markets in Times of Stress. NBER Working Paper 8569.

Reinhart, C., Rogoff, K., 2002. The Modern History of Exchange Rate Arrangements: A Reinterpretation. NBER Working Paper 8963.

Rigobón, R., 2001. The Curse of Non-Investment Grade Countries. NBER Working Paper No. 8636.

van Rijckeghem, C., Weder, B.S., 2000. Spillovers Through Banking Centers - A Panel Data Analysis. IMF Working Papers 00/88, International Monetary Fund, Washington, DC, USA. 
Figure 1

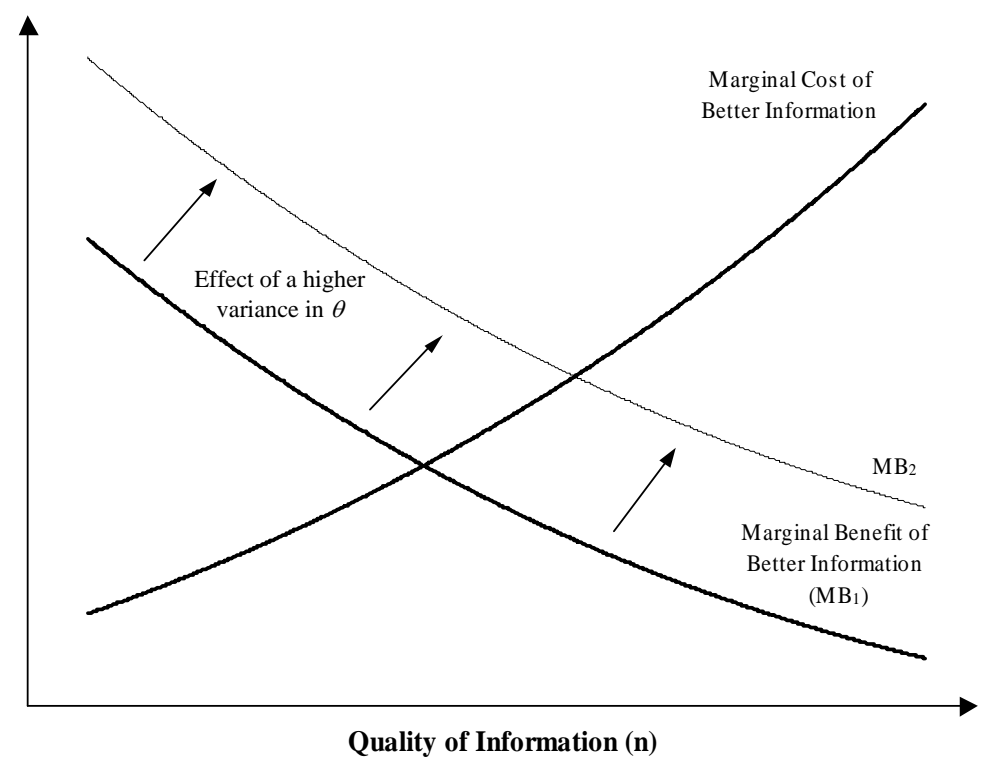


Figure 2

One-Step ahead Forecast Error

of an AR(1) model for the cyclical component of the WPI/CPI ratio
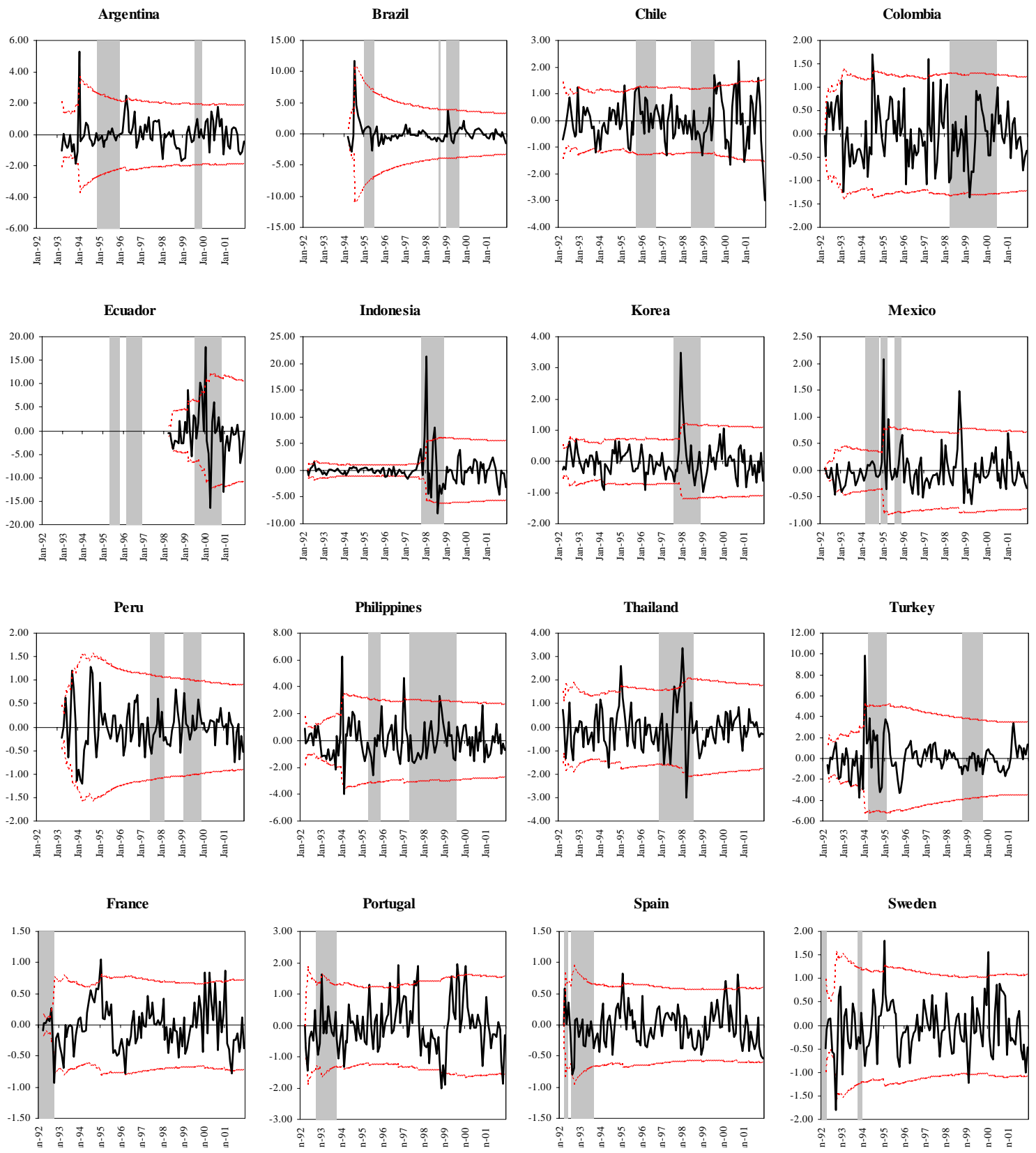

Note: Gray areas indicate Sudden Stop periods. Bands indicate +/- two standard deviations of the forecast error. 
Figure 3a

Conditional Volatility of WPI to CPI ratio and Sudden Stops Emerging Markets
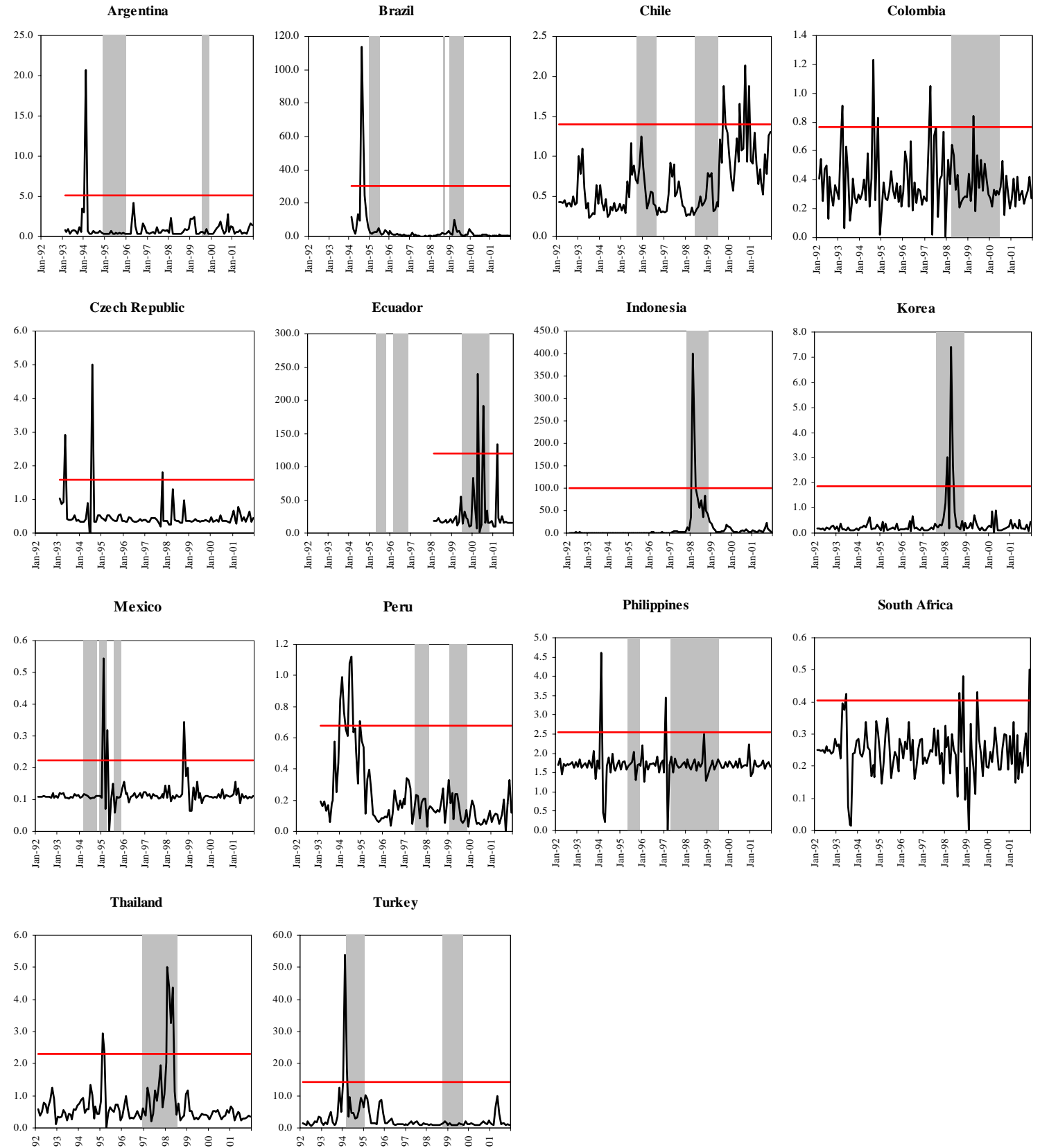

Note: The plotted conditional volatilities are the fitted values for $\sigma_{t}^{2}$ in the system of equations defined in (11) in the main text. Thresholds represent two standard deviations above the mean of the fitted conditional variance $\left(\hat{\sigma}_{t}^{2}\right)$. Gray areas indicate Sudden Stop periods. Nigeria is not included due to lack of data on WPI. 


\section{Figure 3b}

Conditional Volatility of WPI to CPI ratio and Sudden Stops

Developed Economies
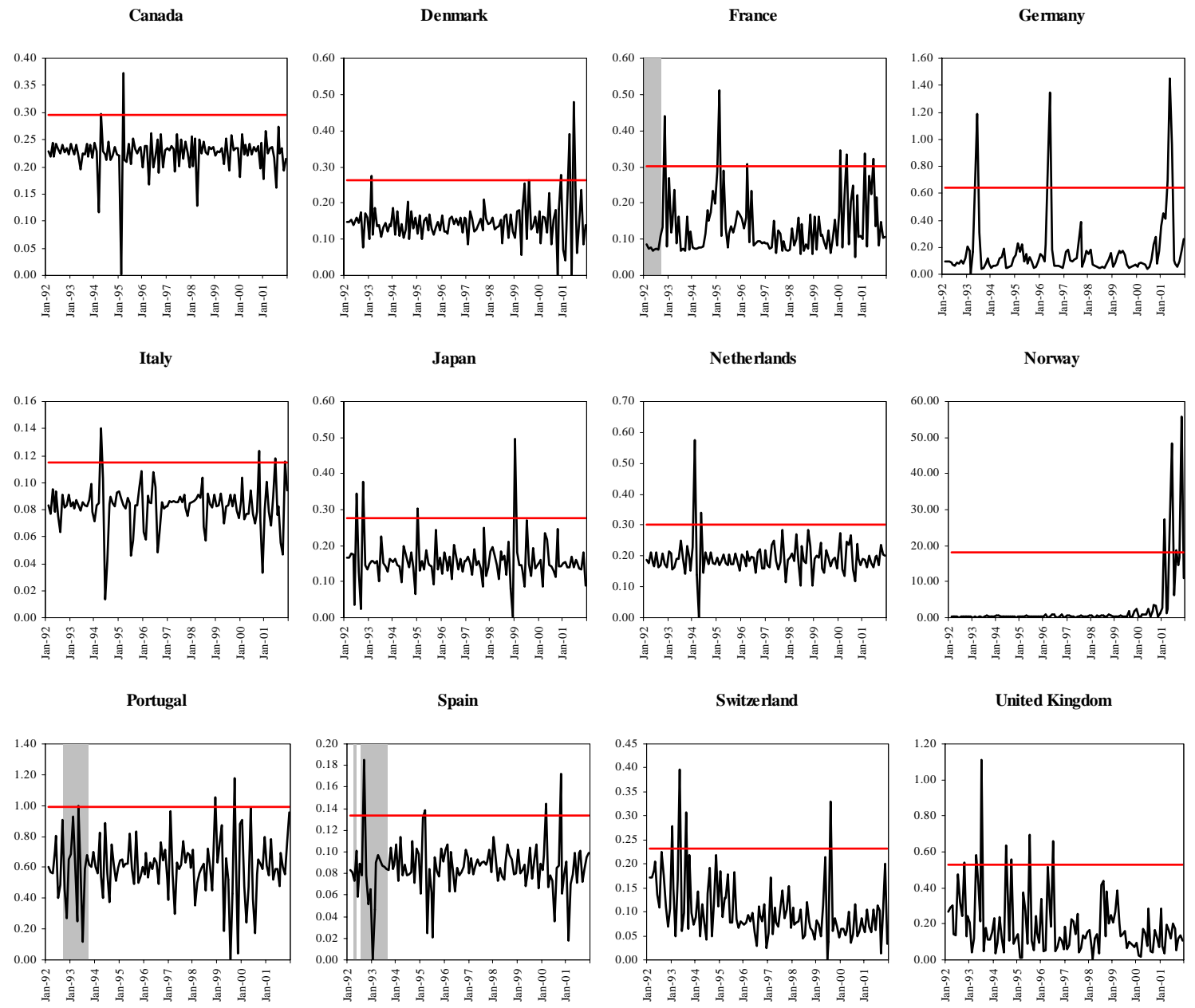

United States

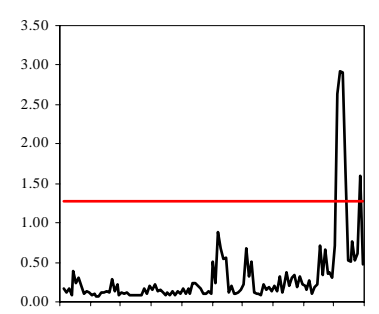

Note: The plotted conditional volatilities are the fitted values for $\sigma_{t}^{2}$ in the system of equations defined in (11) in the main text. Thresholds represent two standard deviations above the mean of the fitted conditional variance $\left(\hat{\sigma}_{t}^{2}\right)$. Gray areas indicate Sudden Stop periods. Australia and New Zealand are not included due to lack of data on WPI. A non-constant variance specification could not be fit to data for Finland and Sweden. 
Table 1

WPI to CPI ratio Volatility during Sudden Stops episodes vis-à-vis tranquil times

Emerging Markets

- Variance in Sudden Stops / variance in tranquil times

2.57

- Variance in Sudden Stops \pm 6 month neighborhood / variance in tranquil times ${ }^{1 /} \quad 4.08$

Developed Economies

- Variance in Sudden Stops / variance in tranquil times

1.65

- Variance in Sudden Stops \pm 6 month neighborhood/ variance in tranquil times ${ }^{1 /}$

2.16

Table 2

Spikes in the WPI/CPI Volatility and Sudden Stops

\begin{tabular}{lcc}
\hline & $\begin{array}{c}\text { Emerging } \\
\text { Markets }\end{array}$ & Ecoveloped \\
Eudden Stops associated with Spikes in WPI/CPI Volatility
\end{tabular}

Emerging Developed

Markets Economies

Spikes in WPI/CPI Volatility associated with Sudden Stops

- Contemporaneously

- In the neighborhood of a SS episode ${ }^{1 /}$

$26 \% \quad 6 \%$

Spikes in WPI/CPI Volatility not associated with Sudden Stops

$15 \% \quad 3 \%$

Total of Spikes in WPI/CPI Volatility

$59 \% \quad 91 \%$

Total of Spikes in WPI/CPI Volatility

$27 \quad 35$

${ }^{1 /}$ A Sudden Stop neighborhood is composed of two additional windows that include six months previous to a Sudden Stop episode, and six months after a Sudden Stop episode. 
Table 3

Panel ARCH(6) Specification of the WPI to CPI Ratio

\begin{tabular}{|c|c|c|c|c|c|c|c|c|}
\hline & (1) & (2) & (3) & (4) & (5) & (6) & (7) & (8) \\
\hline \multicolumn{9}{|c|}{ MEAN EQUATION } \\
\hline \multirow[t]{2}{*}{ Constant } & -0.019 & -0.019 & -0.020 & -0.020 & -0.020 & -0.021 & -0.019 & -0.020 \\
\hline & $(0.007)^{* *}$ & $(0.008)^{* *}$ & $(0.008)^{* *}$ & $(0.008)^{* * *}$ & $(0.008)^{* * *}$ & $(0.008)^{* * *}$ & $(0.008)^{* *}$ & $(0.008)^{* * *}$ \\
\hline \multirow[t]{2}{*}{ WPI/CPI $(\mathrm{t}-1)$} & 1.093 & 1.096 & 1.094 & 1.097 & 1.094 & 1.097 & 1.093 & 1.096 \\
\hline & $(0.017)^{* * *}$ & $(0.017)^{* * *}$ & $(0.017) * * *$ & $(0.017)^{* * *}$ & $(0.017)^{* * *}$ & $(0.017)^{* * *}$ & $(0.017)^{* * *}$ & $(0.017)^{* * *}$ \\
\hline \multirow{2}{*}{$\operatorname{ToT}_{(\mathrm{t}-1)}$} & -0.001 & -0.002 & -0.001 & -0.002 & -0.001 & -0.002 & -0.001 & -0.002 \\
\hline & $(0.002)$ & $(0.002)$ & $(0.002)$ & $(0.002)$ & $(0.002)$ & $(0.002)$ & $(0.002)$ & $(0.002)$ \\
\hline \multirow[t]{2}{*}{ Ind. Production $_{(\mathrm{t}-1)}$} & 0.017 & 0.017 & 0.017 & 0.017 & 0.017 & 0.017 & 0.017 & 0.017 \\
\hline & $(0.003)^{* * *}$ & $(0.004)^{* * *}$ & $(0.003)^{* * *}$ & $(0.004)^{* * *}$ & $(0.003)^{* * *}$ & $(0.004)^{* * *}$ & $(0.003)^{* * *}$ & $(0.004)^{* * *}$ \\
\hline \multirow{2}{*}{$\mathrm{WPI} \mathrm{CPI}(\mathrm{t}-2)$} & -0.249 & -0.251 & -0.250 & -0.252 & -0.250 & -0.252 & -0.249 & -0.251 \\
\hline & $(0.017)^{* * *}$ & $(0.017)^{* * *}$ & $(0.017)^{* * *}$ & $(0.017)^{* * *}$ & $(0.017)^{* * *}$ & $(0.017)^{* * *}$ & $(0.018)^{* * *}$ & $(0.017)^{* * *}$ \\
\hline \multirow{2}{*}{$\operatorname{ToT}_{(\mathrm{t}-2)}$} & -0.001 & -0.001 & -0.001 & -0.001 & -0.001 & -0.001 & -0.001 & -0.001 \\
\hline & $(0.002)$ & $(0.002)$ & $(0.002)$ & $(0.002)$ & $(0.002)$ & $(0.002)$ & $(0.002)$ & $(0.002)$ \\
\hline \multirow[t]{2}{*}{ Ind. Production $(\mathrm{t}-2)$} & 0.002 & 0.002 & 0.002 & 0.002 & 0.002 & 0.002 & 0.002 & 0.002 \\
\hline & $(0.003)$ & $(0.003)$ & $(0.004)$ & $(0.003)$ & $(0.004)$ & $(0.003)$ & $(0.004)$ & $(0.003)$ \\
\hline \multirow[t]{2}{*}{ ToT } & -0.004 & -0.004 & -0.004 & -0.004 & -0.004 & -0.004 & -0.004 & -0.004 \\
\hline & $(0.002)^{* * *}$ & $(0.002)^{* *}$ & $(0.002)^{* *}$ & $(0.002)^{* *}$ & $(0.002)^{* *}$ & $(0.002)^{* *}$ & $(0.002)^{* *}$ & $(0.002) * *$ \\
\hline \multirow[t]{2}{*}{ Sudden Stop } & & & 0.025 & 0.025 & & & -0.027 & -0.025 \\
\hline & & & $(0.035)$ & $(0.035)$ & & & $(0.053)$ & $(0.053)$ \\
\hline \multirow[t]{2}{*}{ Balance sheet effect } & & & & & 0.487 & 0.469 & 0.654 & 0.627 \\
\hline & & & & & $(0.360)$ & $(0.364)$ & $(0.528)$ & $(0.539)$ \\
\hline \\
\hline \multirow[t]{2}{*}{ Constant } & -3.550 & -3.057 & -3.541 & -3.049 & -3.524 & -3.033 & -3.523 & -3.031 \\
\hline & $(0.316)^{* * *}$ & $(0.359)^{* * *}$ & $(0.319)^{* * *}$ & $(0.362)^{* * *}$ & $(0.317)^{* * *}$ & $(0.359)^{* * *}$ & $(0.323)^{* * *}$ & $(0.362)^{* * *}$ \\
\hline \multirow[t]{2}{*}{ EM dummy } & 0.610 & 0.606 & 0.605 & 0.601 & 0.608 & 0.604 & 0.613 & 0.608 \\
\hline & $(0.125)^{* * *}$ & $(0.125)^{* * *}$ & $(0.125)^{* * *}$ & $(0.125)^{* * *}$ & $(0.125)^{* * *}$ & $(0.125)^{* * *}$ & $(0.125)^{* * *}$ & $(0.125)^{* * *}$ \\
\hline \multirow[t]{2}{*}{$\operatorname{DLD}_{(\mathrm{t}-1)}$} & 3.701 & 3.867 & 3.722 & 3.893 & 3.645 & 3.818 & 3.602 & 3.773 \\
\hline & $(0.703)^{* * *}$ & $(0.708)^{* * *}$ & $(0.715) * * *$ & $(0.721)^{* * *}$ & $(0.716)^{* * *}$ & $(0.719)^{* * *}$ & $(0.738)^{* * *}$ & $(0.743)^{* * *}$ \\
\hline \multirow{2}{*}{$(1-\omega)_{(t-1)}$} & 0.472 & 0.432 & 0.464 & 0.423 & 0.450 & 0.407 & 0.450 & 0.406 \\
\hline & $(0.286)^{*}$ & $(0.283)$ & $(0.289)$ & $(0.286)$ & $(0.287)$ & $(0.284)$ & $(0.291)$ & $(0.289)$ \\
\hline \multirow[t]{2}{*}{ Sudden Stop } & 0.769 & 0.763 & 0.750 & 0.743 & 0.756 & 0.748 & 0.768 & 0.761 \\
\hline & $(0.157)^{* * *}$ & $(0.156)^{* * *}$ & $(0.173)^{* * *}$ & $(0.174)^{* * *}$ & $(0.161)^{* * *}$ & $(0.161)^{* * *}$ & $(0.170)^{* * *}$ & $(0.170)^{* * *}$ \\
\hline \multirow[t]{2}{*}{ Ex. Regime RR (t-1) } & & -0.129 & & -0.129 & & -0.128 & & -0.128 \\
\hline & & $(0.050)^{* *}$ & & $(0.050)^{* *}$ & & $(0.051)^{* *}$ & & $(0.051)^{* *}$ \\
\hline \multirow[t]{2}{*}{ ARCH(1) } & 0.260 & 0.259 & 0.261 & 0.260 & 0.259 & 0.258 & 0.258 & 0.257 \\
\hline & $(0.019)^{* * *}$ & $(0.019)^{* * *}$ & $(0.019) * * *$ & $(0.019) * * *$ & $(0.019)^{* * *}$ & $(0.019)^{* * *}$ & $(0.019)^{* * *}$ & $(0.019)^{* * *}$ \\
\hline \multirow[t]{2}{*}{ ARCH(2) } & 0.234 & 0.231 & 0.233 & 0.231 & 0.233 & 0.231 & 0.234 & 0.231 \\
\hline & $(0.016)^{* * *}$ & $(0.016)^{* * *}$ & $(0.016) * * *$ & $(0.016) * * *$ & $(0.016)^{* * *}$ & $(0.016)^{* * *}$ & $(0.016)^{* * *}$ & $(0.016)^{* * *}$ \\
\hline \multirow[t]{2}{*}{ ARCH(3) } & 0.135 & 0.137 & 0.135 & 0.137 & 0.136 & 0.138 & 0.136 & 0.138 \\
\hline & $(0.020)^{* * *}$ & $(0.020)^{* * *}$ & $(0.020) * * *$ & $(0.020) * * *$ & $(0.020)^{* * *}$ & $(0.020)^{* * *}$ & $(0.020)^{* * *}$ & $(0.020)^{* * *}$ \\
\hline ARCH(4) & 0.189 & 0.189 & 0.189 & 0.189 & 0.190 & 0.190 & 0.191 & 0.190 \\
\hline & $(0.018)^{* * *}$ & $(0.018)^{* * *}$ & $(0.018)^{* * *}$ & $(0.018)^{* * *}$ & $(0.018)^{* * *}$ & $(0.018)^{* * *}$ & $(0.018)^{* * *}$ & $(0.018)^{* * *}$ \\
\hline ARCH(5) & 0.031 & 0.025 & 0.031 & 0.025 & 0.030 & 0.024 & 0.029 & 0.024 \\
\hline & $(0.016)^{* *}$ & $(0.015)$ & $(0.016)^{* *}$ & $(0.015)^{*}$ & $(0.016)^{*}$ & $(0.015)$ & $(0.015)^{*}$ & $(0.015)$ \\
\hline ARCH(6) & 0.066 & 0.070 & 0.066 & 0.070 & 0.067 & 0.071 & 0.068 & 0.072 \\
\hline & $(0.018)^{* * *}$ & $(0.018)^{* * *}$ & $(0.018)^{* * *}$ & $(0.018)^{* * *}$ & $(0.018)^{* * *}$ & $(0.019)^{* * *}$ & $(0.018)^{* * *}$ & $(0.019)^{* * *}$ \\
\hline
\end{tabular}

Standard errors in parentheses. * significant at $10 \%$; ** significant at $5 \%$; *** significant at $1 \%$

Note: Panel ARCH is estimated using an unbalanced sample of 29 countries for the period 1992-

2001. Note that the first two years of observations (1990-1991) are lost, given that such

information is used to construct initial standard deviations to make a judgment on the size of capital flow reversals. See Data appendix for definitions of variables and data sources. The estimated system is described in equations (12) and (13) in the main text. 
Table 4

Panel ARCH(6) Specification of the WPI to CPI Ratio (12-month lags in variance equation)

\begin{tabular}{|c|c|c|c|c|c|c|c|c|}
\hline & $(1)$ & $(2)$ & $(3)$ & $(4)$ & (5) & (6) & $(7)$ & $(8)$ \\
\hline \multicolumn{9}{|c|}{ MEAN EQUATION } \\
\hline \multirow[t]{2}{*}{ Constant } & -0.018 & -0.017 & -0.019 & -0.019 & -0.018 & -0.018 & -0.019 & -0.019 \\
\hline & $(0.007)^{* *}$ & $(0.008)^{* *}$ & $(0.008)^{* *}$ & $(0.008)^{* *}$ & $(0.008)^{* *}$ & $(0.008)^{* *}$ & $(0.008)^{* *}$ & $(0.008)^{* *}$ \\
\hline \multirow[t]{2}{*}{ WPI/CPI $(\mathrm{t}-1)$} & 1.089 & 1.090 & 1.089 & 1.091 & 1.089 & 1.090 & 1.089 & 1.091 \\
\hline & $(0.017)^{* * *}$ & $(0.017)^{* * *}$ & $(0.017)^{* * *}$ & $(0.017)^{* * *}$ & $(0.017)^{* * *}$ & $(0.017)^{* * *}$ & $(0.017) * * *$ & $(0.017)^{* * *}$ \\
\hline \multirow[t]{2}{*}{$\operatorname{ToT}_{(\mathrm{t}-1)}$} & -0.002 & -0.003 & -0.002 & -0.003 & -0.002 & -0.003 & -0.002 & -0.003 \\
\hline & $(0.002)$ & $(0.002)$ & $(0.002)$ & $(0.002)$ & $(0.002)$ & $(0.002)$ & $(0.002)$ & $(0.002)$ \\
\hline \multirow{2}{*}{ Ind. Production $(\mathrm{t}-1)$} & 0.017 & 0.017 & 0.018 & 0.018 & 0.017 & 0.018 & 0.018 & 0.018 \\
\hline & $(0.004)^{* * *}$ & $(0.004)^{* * *}$ & $(0.004)^{* * *}$ & $(0.004)^{* * *}$ & $(0.004)^{* * *}$ & $(0.004)^{* * *}$ & $(0.004)^{* * *}$ & $(0.004)^{* * *}$ \\
\hline \multirow{2}{*}{$\mathrm{WPI}_{\mathrm{CPI}}(\mathrm{t}-2)$} & -0.246 & -0.245 & -0.247 & -0.246 & -0.246 & -0.246 & -0.247 & -0.246 \\
\hline & $(0.018)^{* * *}$ & $(0.017)^{* * *}$ & $(0.018)^{* * *}$ & $(0.017)^{* * *}$ & $(0.018)^{* * *}$ & $(0.017)^{* * *}$ & $(0.018) * * *$ & $(0.017)^{* * *}$ \\
\hline \multirow[t]{2}{*}{$\operatorname{ToT}_{(\mathrm{t}-2)}$} & -0.001 & -0.001 & -0.001 & -0.001 & -0.001 & -0.001 & -0.001 & -0.001 \\
\hline & $(0.002)$ & $(0.002)$ & $(0.002)$ & $(0.002)$ & $(0.002)$ & $(0.002)$ & $(0.002)$ & $(0.002)$ \\
\hline \multirow{2}{*}{ Ind. Production $(\mathrm{t}-2)$} & 0.003 & 0.003 & 0.003 & 0.002 & 0.003 & 0.002 & 0.003 & 0.002 \\
\hline & $(0.004)$ & $(0.003)$ & $(0.004)$ & $(0.004)$ & $(0.004)$ & $(0.004)$ & $(0.004)$ & $(0.004)$ \\
\hline \multirow[t]{2}{*}{ ToT } & -0.006 & -0.006 & -0.005 & -0.005 & -0.005 & -0.005 & -0.005 & -0.005 \\
\hline & $(0.002)^{* * *}$ & $(0.002)^{* * *}$ & $(0.002)^{* * *}$ & $(0.002)^{* * *}$ & $(0.002)^{* * *}$ & $(0.002)^{* * *}$ & $(0.002) * * *$ & $(0.002)^{* * *}$ \\
\hline \multirow[t]{2}{*}{ Sudden Stop } & & & 0.035 & 0.042 & & & 0.035 & 0.036 \\
\hline & & & (0.039) & $(0.040)$ & & & $(0.071)$ & $(0.070)$ \\
\hline \multirow{2}{*}{ Balance sheet effect } & & & & & 0.260 & 0.357 & -0.007 & 0.087 \\
\hline & & & & & $(0.347)$ & $(0.372)$ & $(0.625)$ & $(0.634)$ \\
\hline \multicolumn{9}{|c|}{$\mathrm{N}$} \\
\hline \multirow[t]{2}{*}{ Constant } & -3.847 & -3.479 & -3.874 & -3.483 & -3.901 & -3.517 & -3.872 & -3.492 \\
\hline & $(0.310)^{* * *}$ & $(0.398)^{* * *}$ & $(0.320)^{* * *}$ & $(0.398)^{* * *}$ & $(0.314)^{* * *}$ & $(0.398)^{* * *}$ & $(0.321)^{* * *}$ & $(0.399)^{* * *}$ \\
\hline \multirow[t]{2}{*}{ EM dummy } & 0.731 & 0.723 & 0.730 & 0.721 & 0.739 & 0.733 & 0.730 & 0.723 \\
\hline & $(0.125)^{* * *}$ & $(0.126)^{* * *}$ & $(0.125)^{* * *}$ & $(0.126)^{* * *}$ & $(0.126)^{* * *}$ & $(0.127)^{* * *}$ & $(0.126)^{* * *}$ & $(0.127)^{* * *}$ \\
\hline \multirow[t]{2}{*}{$\operatorname{DLD}_{(\mathrm{t}-12)}$} & 3.041 & 3.105 & 3.073 & 3.149 & 3.023 & 3.073 & 3.074 & 3.136 \\
\hline & $(0.722)^{* * *}$ & $(0.729)^{* * *}$ & $(0.752)^{* * *}$ & $(0.762)^{* * *}$ & $(0.726)^{* * *}$ & $(0.737)^{* * *}$ & $(0.783) * * *$ & $(0.794)^{* * *}$ \\
\hline \multirow{2}{*}{$(1-\varpi)_{(\mathrm{t}-12)}$} & 0.735 & 0.659 & 0.758 & 0.678 & 0.786 & 0.711 & 0.757 & 0.688 \\
\hline & $(0.278)^{* * *}$ & $(0.292)^{* *}$ & $(0.285)^{* * *}$ & $(0.295)^{* *}$ & $(0.283)^{* * *}$ & $(0.293)^{* *}$ & $(0.288)^{* * *}$ & $(0.295)^{* *}$ \\
\hline \multirow[t]{2}{*}{ Sudden Stop } & 0.892 & 0.916 & 0.880 & 0.896 & 0.914 & 0.939 & 0.879 & 0.905 \\
\hline & $(0.157)^{* * *}$ & $(0.155)^{* * *}$ & $(0.169)^{* * *}$ & $(0.170)^{* * *}$ & $(0.155)^{* * *}$ & $(0.152)^{* * *}$ & $(0.202)^{* * *}$ & $(0.200)^{* * *}$ \\
\hline \multirow[t]{2}{*}{ Ex. Regime RR (t-12) } & & -0.085 & & -0.091 & & -0.090 & & -0.091 \\
\hline & & $(0.046)^{*}$ & & $(0.048)^{*}$ & & $(0.046)^{*}$ & & $(0.048)^{*}$ \\
\hline \multirow[t]{2}{*}{ ARCH(1) } & 0.256 & 0.258 & 0.258 & 0.260 & 0.256 & 0.258 & 0.258 & 0.260 \\
\hline & $(0.018)^{* * *}$ & $(0.018)^{* * *}$ & $(0.018)^{* * *}$ & $(0.019)^{* * *}$ & $(0.018)^{* * *}$ & $(0.018)^{* * *}$ & $(0.018) * * *$ & $(0.019)^{* * *}$ \\
\hline \multirow[t]{2}{*}{$\mathrm{ARCH}(2)$} & 0.220 & 0.220 & 0.220 & 0.219 & 0.219 & 0.219 & 0.220 & 0.219 \\
\hline & $(0.016)^{* * *}$ & $(0.016)^{* * *}$ & $(0.016)^{* * *}$ & $(0.016)^{* * *}$ & $(0.016)^{* * *}$ & $(0.016)^{* * *}$ & $(0.016) * * *$ & $(0.016)^{* * *}$ \\
\hline \multirow[t]{2}{*}{ ARCH(3) } & 0.143 & 0.144 & 0.143 & 0.145 & 0.143 & 0.145 & 0.143 & 0.145 \\
\hline & $(0.021)^{* * *}$ & $(0.021)^{* * *}$ & $(0.020)^{* * *}$ & $(0.020)^{* * *}$ & $(0.020)^{* * *}$ & $(0.020)^{* * *}$ & $(0.021)^{* * *}$ & $(0.020)^{* * *}$ \\
\hline $\mathrm{ARCH}(4)$ & 0.185 & 0.185 & 0.184 & 0.184 & 0.185 & 0.185 & 0.184 & 0.184 \\
\hline & $(0.018)^{* * *}$ & $(0.018)^{* * *}$ & $(0.018)^{* * *}$ & $(0.018)^{* * *}$ & $(0.018)^{* * *}$ & $(0.018)^{* * *}$ & $(0.018) * * *$ & $(0.018)^{* * *}$ \\
\hline ARCH(5) & 0.033 & 0.028 & 0.033 & 0.028 & 0.033 & 0.027 & 0.033 & 0.028 \\
\hline & $(0.015)^{* *}$ & $(0.015)^{*}$ & $(0.015)^{* *}$ & $(0.015)^{*}$ & $(0.015)^{* *}$ & $(0.015)^{*}$ & $(0.016)^{* *}$ & $(0.015)^{*}$ \\
\hline ARCH(6) & 0.088 & 0.091 & 0.088 & 0.092 & 0.089 & 0.093 & 0.088 & 0.092 \\
\hline & $(0.018)^{* * *}$ & $(0.018)^{* * *}$ & $(0.018)^{* * *}$ & $(0.018)^{* * *}$ & $(0.018)^{* * *}$ & $(0.018)^{* * *}$ & $(0.018)^{* * *}$ & $(0.018)^{* * *}$ \\
\hline
\end{tabular}

Standard errors in parentheses. * significant at 10\%; ** significant at 5\%; *** significant at $1 \%$.

Note: Panel ARCH is estimated using an unbalanced sample of 29 countries for the period 1992-

2001. Note that the first two years of observations (1990-1991) are lost, given that such information is used to construct initial standard deviations to make a judgment on the size of capital flow reversals. See Data appendix for definitions of variables and data sources. The estimated system is described in equations (12) and (13) in the main text. In contrast to Table 3, Domestic Liability Dollarization $(D L D)$, the indicator of potential change in relative prices $(1-\varpi)$ and the Exchange Rate Regime variable (Ex. Regime $R R$ ) are lagged 12 periods in the variance equation. 